\title{
What would you do?
}

\author{
Stephen Hancocks OBE \\ Editor-in-Chief
}

I am sure that it is apocryphal but the story goes that a final year dental student, when asked what his thoughts were on ethics, replied that as far as English counties went it was a nice enough place but on balance he preferred Sussex.

The tale may be based on the mispronunciation or the mishearing of the word but the underlying inference is that as a subject, ethics is of so little relevance that even at finals it does not occur to a candidate as being of more importance than a question about geography. It is this central dilemma that we often face in dentistry where on a day-to-day basis we are more frequently engaged by 'doing things' rather than thinking about things. Verbs are 'doing words' and dentistry as a verb is definitely a 'doing' profession rather than a philosophical one.

It was with this in mind that I recently read a research paper from the Netherlands in which the authors had posed ethical and legal dilemmas to dental students at the beginning and end of their undergraduate careers. ${ }^{1}$ The study was modelled on previous work in the USA in which the subjects had been asked two questions; what is the 'correct' (ie ethical) course of action and, what did they think dentists would actually do? However, in the present instance a third question was added, which was, 'what would you do?'

Now, one might reasonably expect that the three answers should be consistent. The correct ethical course is identified, is viewed as being followed by dentists and is confirmed as being the actions that they, the respondent, would also undertake. Not so. The study shows that the knowledge level of students in the area of health law increases between the first and fifth year but their knowledge of ethics decreases. The first year students did poorly in answering both the questions with a legal basis as well as those on an ethical basis, which might be predictable but does contradict the often repeated contention by dental students that they do not need to take a course a dental ethics because they are already ethically mature.

\section{DECREASED KNOWLEDGE WITH TIME}

Far more troublesome was the finding that students' knowledge of ethics did not increase. In fact, fifth year students scored significantly lower than their freshmen peers, only 13\% of the seniors giving the ethically correct answer in at least three of the five scenarios; not a single individual answered all five correctly and $8 \%$ answered all five questions wrongly. Even more remarkable was the finding that large numbers of students are not consistent, that is, the way they plan to behave does not coincide with what they say is the morally correct way to behave.

There are cautions here that we need to add. Firstly, ethics have to be set to some extent within the cultural and societal values of the communities in which the activities are to take place. Additionally, in this instance, the educational system and curricula may be very different in the Netherlands compared with other countries. However, the variation between the Netherlands and, say, the UK or indeed 'western' societies in general is not likely to be so great as to make the results of this survey radically different enough to suggest that they cannot be applied to other dental students; or indeed dentists.

What I think so fascinating are the gaps that can appear between the two gradations of the three questions. The differences in what is perceived as being the correct action and what essentially one thinks everyone else should do (and would do) and the further disconnect between that stance and what one should and would do oneself. All of which is to be human first and professional second; or should that be the other way around? By being professional do we have to rise above the impulse of being human, to attend first to the higher aspirations of what is 'right' rather than what is biologically dictated by the survival instinct?

We have published several pieces in recent times in the journal about the definition and place of professionalism and I am aware that these can seem rather dry and divorced from the 'doing' of dentistry. Yet, a read through recent $B D J$ letters pages shows that such dilemmas are in fact the stuff of daily decision making. Correspondents questioning the morality of not providing the option of endodontics under the NHS because of a judgment over the realism of the fee, the turning away or otherwise of emergency patients and the inclusion, or not, of a comprehensive set of treatment options based on prejudices or preconceptions of cost, availability and (ironically) professional opinion as to their veracity.

Whether we live in Sussex, the Netherlands or any other country in which the 'doing' of dentistry forms our work then we also need to dwell in the realm of ethics and not under the illusion that it is somehow a world apart.

1. Brands W G, Bronkhorst E M, Welie J V M. The chasm between knowing and choosing the ethical course of action. A survey of dental students in the Netherlands. Int Dent J 2010; 60: 321-328.

DOI: 10.1038/sj.bdj.2010.982 